(2) Open Access Full Text Article

ORIGINAL RESEARCH

\title{
Impact of symptom variability on clinical outcomes in COPD: analysis of a longitudinal cohort
}

This article was published in the following Dove Press journal: International Journal of Chronic Obstructive Pulmonary Disease

\author{
Mi-Ae Kim' \\ Min-Kang Suh' \\ Jisoo Park' \\ Jung-Hyun Kim' \\ Tae-Hoon Kim' \\ Eun Kyung Kim' \\ Yeon-Mok $\mathrm{Oh}^{2}$ \\ Sang-Do Lee ${ }^{2}$ \\ Ji-Hyun Lee'
}

'Department of Pulmonology, Allergy and Critical Care Medicine, CHA Bundang Medical Center, CHA

University, Seongnam, Republic of Korea;

${ }^{2}$ Department of Pulmonary and Critical

Care Medicine, Asan Medical Center,

University of Ulsan College of Medicine,

Seoul, Republic of Korea
Correspondence: Ji-Hyun Lee

Department of Pulmonology, Allergy and

Critical Care Medicine, CHA Bundang

Medical Center, CHA University, 59

Yatap-ro, Bundang-gu, Seongnam 463-7I2,

Republic of Korea

Tel +82 3I 7805205

Fax +82 31 7802992

Email plmjhlee@cha.ac.kr
Purpose: We compared clinical characteristics of COPD patients according to symptom variability and evaluated the effect of symptom variability during the first year of enrollment on clinical outcomes of COPD.

Methods: We analyzed COPD patients' data from the Korean Obstructive Lung Disease (KOLD) cohort. Symptom variability was defined based on the value of standard deviation (SD) of mMRC scores obtained every 3 months during the follow-up period of the first year. Patients were divided into 2 groups: the consistent (SD of $\mathrm{mMRC}$ scores $=0$ ) and variable ( $\mathrm{SD}$ of mMRC scores $>0$ ) groups. Clinical characteristics and outcomes were compared in terms of symptom variability.

Results: A total of 407 patients were included in the analysis. Patient age was 67.2 years and $97.8 \%$ of the subjects were male. Initial mMRC was 1.5 and the SD of mMRC scores during the first year was 0.5 . There were 137 subjects $(33.7 \%)$ in the consistent group and 270 $(66.3 \%)$ in the variable group. The variable group showed a lower $\operatorname{FEV}_{1}(P=0.019)$ and a higher mMRC score $(P=0.001)$. The annual incidence of acute exacerbation of COPD (AECOPD) tended to be higher in the variable group $(P=0.078)$ and that of severe AE-COPD was higher in the variable group than in the consistent group $(P=0.002)$. The variable group showed a higher proportion of annual exacerbators $(P=0.001)$ and frequent exacerbators $(P=0.017)$. In multivariate logistic regression analysis, the variable group was significantly associated with annual exacerbators $(\mathrm{OR}=1.963, P=0.011)$ and frequent exacerbators (OR $=2.090, P=0.055)$.

Conclusion: COPD patients with symptom variability may have higher exacerbation risk as well as lower lung function and more severe respiratory symptoms.

Keywords: COPD, symptom, variability, exacerbation, death, lung function

\section{Introduction}

Chronic obstructive pulmonary disease (COPD) is characterized by chronic airflow limitation and persistent respiratory symptoms, such as dyspnea, cough, and/or sputum production. It is the fourth leading cause of death worldwide and is predicted to be the third leading cause of death by 2020. Chronic and progressive dyspnea is the most typical sign of COPD, and respiratory symptoms in COPD have been more highlighted nowadays. ${ }^{1}$ Since 2011, patients' symptoms, assessed by modified Medical Research Council questionnaire (mMRC) or COPD Assessment Test $\left(\mathrm{CAT}^{T M}\right)$, have been introduced in the global initiative for chronic obstructive lung disease (GOLD) COPD treatment guideline. 
Symptom variability is the most important feature of asthma. COPD symptoms have been considered "persistent and progressive in nature," though there is increasing evidence that patients with COPD also experience symptom variability within days and weeks, especially in severe cases. $^{2-5}$ There are a few studies on symptom variability in COPD. According to the studies, about half of the patients perceive symptom variations and morning is the most troublesome time of the day. ${ }^{2-4,6,7}$ Moreover, morning symptoms are inversely associated with physical activity as well as exacerbation risk and poor health-related quality of life (HRQOL) ${ }^{6,8,9}$ However, symptom variability was defined using the self-reported question, "Do you have symptom variability during the day or week?" rather than adopting numerical scales, such as mMRC, St. George's Respiratory Questionnaire (SGRQ) and CAT. ${ }^{2}$ In addition, symptom alteration was assessed for $24 \mathrm{hrs}$ by comparing among morning, day, and night ${ }^{4,5,7-9}$ instead of a long duration of time using arithmetical calculations, eg, standard deviation (SD), standard error, and coefficient of variation (the ratio between standard deviation and mean). ${ }^{10-12}$ In this context, it is noteworthy that COPD patients present symptom variability during a long-term follow-up and its impact on clinical outcomes of COPD, such as exacerbations and deaths.

The present study evaluated the effect of symptom variability during the first year of enrollment on clinical outcomes in our KOLD COPD cohort using the numerical symptom scoring system. We divided patients into 2 groups according to the mMRC symptom variability during the study period, compared the clinical characteristics of COPD patients according to symptom variability, and evaluated the effect of symptom variability during the follow-up period on exacerbations and deaths.

\section{Materials and methods Subjects}

COPD patients were retrieved from the Korean Obstructive Lung Disease (KOLD) cohort, which was prospectively recruited in 17 centers in South Korea between June 2005 and May 2017 according to the following criteria: (1) less than 0.7 for post-bronchodilator $\mathrm{FEV}_{1} / \mathrm{FVC}$ (forced expiratory volume in $1 \mathrm{~second} /$ forced vital capacity) after inhalation of $400 \mu \mathrm{g}$ albuterol, (2) more than 10 pack-year of smoking history, and (3) minimal or no abnormalities on chest radiographs. ${ }^{13,14}$ Among these COPD patients, we included those who completed mMRC more than 3 times during the first year of enrollment.

\section{Collection of clinical data in the KOLD cohort}

Baseline demographic and clinical data including age, sex, smoking, body mass index (BMI), family history of bronchial asthma (BA), Charlson's comorbidity score, blood eosinophil count $\left(/ \mathrm{mm}^{3}\right)$, and previous history of exacerbations within 1 year, were collected from all patients. Pre- and post-bronchodilator spirometry results, diffusing capacity, lung volume using $\mathrm{V}_{\max 22}$ (SensorMedics, Yorba Linda, CA, USA; PFDX instrument, MedGraphics, St Paul, MN, USA) and 6 min walk distance (6MWD) were performed according to American Thoracic Society guidelines. ${ }^{15}$

During the follow-up in the KOLD cohort, each patient regularly visited the clinic every 3 months. Clinical information on medication history, smoking status, mMRC score, $\mathrm{CAT}^{T M}$, and acute exacerbation history during the previous 3 months were obtained at each visit; pre- and post-bronchodilator spirometry was performed at 6-month intervals; diffusing capacity, lung volume, 6MWD, and SGRQ score were checked yearly. ${ }^{13}$ At the time of enrollment, non-severe patients discontinued regular medications at least 2 weeks before the time of enrollment, while severe patients whose condition did not allow cessation of medications continued their regular medications. Severe patients' spirometry results and mMRC scores were all used in the analysis because they continued regular medications at the time of enrollment. However, we did not use the initial spirometry results and mMRC scores in non-severe patients who had a wash-out period before the enrollment because improvement in mMRC scores after initiation of treatment could be considered "variable."

\section{Definition of symptom variability}

We calculated each patient's SD of mMRC scores during the first year. Patients were divided into 2 groups according to the SD value of mMRC scores. The cut-off SD value of " 0 " was used to help clinicians assess symptom variability in clinical practice. The consistent group was defined when the SD of mMRC scores was 0 during the first year of enrollment and mMRC scores were not changed. The variable group was defined when the SD of mMRC scores was greater than 0 during the first year and $\mathrm{mMRC}$ scores were changed. 


\section{Definition of clinical outcomes}

Acute exacerbation of COPD (AE-COPD) was defined as worsening of symptoms (dyspnea, cough, or sputum) requiring treatment with systemic steroids and/or antibiotics. Severe AE-COPD was defined as hospitalization or visiting the emergency department due to exacerbation. ${ }^{1}$ The annual incidences of AE-COPD and severe AECOPD were calculated by dividing total exacerbation number by follow-up duration. An annual exacerbator was defined when a COPD patient who experienced 1 or more exacerbations per year (annual incidence of AECOPD $\geq 1$ ). A frequent exacerbator was defined as a patient who experienced 2 or more non-severe exacerbations per year (annual incidence of $\mathrm{AE}-\mathrm{COPD} \geq 2$ ), or 1 or more severe exacerbations per year (annual incidence of severe AE-COPD $\geq 1$ ). Annual declines in post-bronchodilator $\mathrm{FEV}_{1}$ and SGRQ scores were analyzed by randomslope and random-intercept mixed linear regression as previously mentioned. ${ }^{16}$ Mortality data were also collected during the follow-up period.

\section{Statistical analysis}

Clinical characteristics were compared according to symptom variability using Student's $t$-test for continuous data and the chi-square test for categorical data. Association analyses were performed using Pearson's correlation coefficient among continuous data and logistic regression analysis when dependent data are categorical. Cox-proportional hazard ratio analysis was applied to assess mortality risk. Descriptive statistics are presented as mean \pm standard deviation for continuous data and number (percentage) for categorical data. Receiver operating characteristic (ROC) curve analysis was conducted using SD values of mMRC scores to determine annual exacerbators and frequent exacerbators.

All tests were two-sided and a $P$-value of less than 0.05 was considered significant. Statistical analyses were conducted using SPSS v.18.0 (IBM Corp., Armonk, NY, USA).

\section{Ethics statement}

This study was approved by the Institutional Review Board of each hospital: University of Ulsan; Seoul National University; Bundang Seoul National University; Hanyang University; Yonsei University; Kangwon National University; Inje University; Bundang CHA Hospital; Ewha Womans University; Korea University; Sungkyunkwan University; Hallym University; Ajou University; Konkuk University; Catholic University;
Kyung Hee University; National Medical Center. Written informed consent was obtained from each patient.

\section{Results}

\section{Baseline characteristics}

Among 664 patients from the total KOLD cohort, 537 met COPD inclusion criteria. We retrieved 407 patients who completed mMRC more than 3 times during the first year of enrollment to evaluate the variability of symptom scores. Baseline characteristics are presented in Table 1. Patient age was 67.2 years and $97.8 \%$ of subjects were male. Current smokers were $29.2 \%$ and smoking amount was 46.3 packyear. The mean $\mathrm{FEV}_{1}$ (\% predicted) was $57.4 \%$ and blood eosinophil count was $279.6 / \mathrm{mm}^{3}$. Initial mMRC score was 1.5 and the SD of mMRC scores during the first year of enrollment was 0.5 . There were 137 subjects (33.7\%) in the consistent group (SD of mMRC scores $>0$ ) and the remaining $(66.3 \%)$ were in the variable group (SD of $\mathrm{mMRC}>0$ ).

\section{Comparison of clinical characteristics between the consistent and variable groups}

When comparing baseline clinical parameters according to symptom variability, the variable group showed lower $\mathrm{FEV}_{1}$,

Table I Baseline characteristics of the subjects

\begin{tabular}{|c|c|}
\hline Parameter $(\mathrm{N}=407)$ & $\begin{array}{l}\text { Mean } \pm \text { SD, } n \\
(\%)\end{array}$ \\
\hline Age, years & $67.2 \pm 7.6$ \\
\hline Male & $398(97.8)$ \\
\hline Smoking amount, pack-year & $46.3 \pm 25.2$ \\
\hline Current smoker $(n=394)$ & II5 (29.2) \\
\hline BMI, $\mathrm{kg} / \mathrm{m}^{2}$ & $23.0 \pm 3.2$ \\
\hline Family history of BA $(n=369)$ & $62(16.8)$ \\
\hline FEV (\% predicted) & $57.4 \pm 17.5$ \\
\hline 6MWD, m (n=384) & $421.3 \pm 85.1$ \\
\hline Charlson's comorbidity score & $1.3 \pm 0.6$ \\
\hline Blood eosinophil count $\left(/ \mathrm{mm}^{3}, \mathrm{n}=355\right)$ & $279.6 \pm 326.7$ \\
\hline mMRC, initial & $1.5 \pm 1.0$ \\
\hline SD of mMRC during I year & $0.5 \pm 0.4$ \\
\hline $\begin{array}{l}\text { SD of mMRC during I year }=0 \text { (Consistent } \\
\text { group) }\end{array}$ & $137(33.7)$ \\
\hline SD of $m M R C$ during I year $>0$ (Variable group) & $270(66.3)$ \\
\hline SGRQ $(n=391)$ & $31.2 \pm 17.6$ \\
\hline SGRQ decline $(n=337)$ & $-0.2 \pm 1.3$ \\
\hline FEV , decline $(\mathrm{mL} /$ year, $\mathrm{n}=337)$ & $-24.3 \pm 24.9$ \\
\hline
\end{tabular}

Notes: Data are presented as $\mathrm{n}(\%)$ or mean \pm SD.

Abbreviations: SD, standard deviation; BMI, body mass index; BA, bronchial asthma; $\mathrm{FEV}_{\mathrm{l}}$, forced expiratory volume in I second; 6MWD, 6 min walk distance; mMRC, modified Medical Research Council; SGRQ, St. George's Respiratory Questionnaire. 
higher mMRC scores and higher SGRQ scores than the consistent group, which means worse respiratory symptoms (Table 2). However, the other clinical characteristics were not significantly different between the 2 groups: age, sex, smoking, BMI, family history of 6MWD, comorbidity, blood eosinophils, and declines in $\mathrm{FEV}_{1}$ and SGRQ.

\section{Comparison of exacerbation and}

\section{mortality between the consistent and variable groups}

Table 3 shows comparisons of exacerbation and mortality according to symptom variability. There were 77 subjects $(19.7 \%)$ who had a history of AE-COPD in the previous year, and the incidence of AE-COPD in the previous year showed no difference between the consistent and variable groups. During the follow-up period, AE-COPD occurred in $60.7 \%$ of the total COPD patients and severe AE-COPD occurred in $23.6 \%$ of them. Among 407 subjects, 120 were annual exacerbators $(29.5 \%)$ and 56 were frequent exacerbators $(13.8 \%)$. Fifty-one patients $(15.5 \%)$ died during the follow-up period.

AE-COPD occurred more frequently in the variable group than in the consistent group $(65.9 \%$ vs $50.4 \%$, $P=0.002)$. The annual incidence of AE-COPD tended to be higher in the variable group than in the consistent group (1.1/ year vs $0.5 /$ year, $P=0.078$; Figure $1 \mathrm{~A}$ ). Severe AE-COPD occurred more frequently in the variable group than in the consistent group ( $28.1 \%$ vs $14.6 \%, P=0.002)$. The incidence of annual severe AE-COPD was higher in the variable group than in the consistent group $(0.2$ /year vs 0.1 /year, $P=0.002$; Figure 1B). The proportions of annual exacerbators and frequent exacerbators were both higher in the variable group than in the consistent group $(34.8 \%$ vs $19 \%, P=0.001$ and $16.7 \%$ vs $8 \%, P=0.017$; respectively) (Figure 2 ). Time to the first COPD exacerbation was shorter in the variable group than in the consistent group, for symptom variability during follow-up period $(P=0.056)$ and the risk was higher in the variable group than in the consistent group (Figure S1).

We also found a weak but significant correlation between the degree of $\mathrm{mMRC}$ variability (SD of mMRC scores) and annual severe AE-COPD incidence ( $r=0.106$, $P=0.033$; data not shown).

\section{Association of symptom variability with annual and frequent exacerbators}

Logistic regression analysis was performed to analyze risk factors for annual exacerbators. Multivariate analysis was conducted using parameters with $P$-values $\leq 0.1$ in univariate analysis. The SD of mMRC scores was not included in the multivariate analysis, but being in the variable or consistent group was included instead. Lung function $\left(\mathrm{FEV}_{1}\right)$, previous history of exacerbation, and being in the variable group were independent risk factors for annual exacerbators (Table 4).

Table 2 Comparison of baseline characteristics according to symptom variability

\begin{tabular}{|c|c|c|c|}
\hline Parameter $(\mathrm{N}=407)$ & Consistent group $(n=137)$ & $\begin{array}{l}\text { Variable group } \\
(n=270)\end{array}$ & $P$-value \\
\hline Age, years & $66.9 \pm 8.0$ & $67.3 \pm 7.5$ & 0.545 \\
\hline Male & $136(99.3)$ & $262(97.0)$ & 0.148 \\
\hline Smoking amount, pack-year & $46.0 \pm 24.2$ & $46.5 \pm 25.8$ & 0.857 \\
\hline Current smoker $(n=394)$ & $42(32.8)$ & $73(27.4)$ & 0.272 \\
\hline BMI, $\mathrm{kg} / \mathrm{m}^{2}$ & $23.0 \pm 3.1$ & $23.0 \pm 3.3$ & 0.914 \\
\hline Family history of BA $(n=369)$ & $22(17.7)$ & $40(16.3)$ & 0.731 \\
\hline $\mathrm{FEV}_{\mathrm{I}}(\%$ predicted $) *$ & $60.2 \pm 15.7$ & $55.9 \pm 18.3$ & 0.019 \\
\hline 6MWD, m (n=384) & $421.6 \pm 86.5$ & $42 I . I \pm 84.5$ & 0.963 \\
\hline Charlson's comorbidity score & $1.4 \pm 0.8$ & $1.2 \pm 0.5$ & 0.186 \\
\hline Blood eosinophil count $\left(/ \mathrm{mm}^{3}, \mathrm{n}=355\right)$ & $281.8 \pm 240.9$ & $278.6 \pm 359.9$ & 0.932 \\
\hline mMRC, initial* & $1.3 \pm 0.8$ & $1.6 \pm 1.0$ & 0.001 \\
\hline SD of mMRC during I year* & $0 \pm 0$ & $0.7 \pm 0.3$ & $<0.001$ \\
\hline SGRQ $(n=391)^{*}$ & $27.3 \pm 16.5$ & $33.0 \pm 17.9$ & 0.002 \\
\hline SGRQ decline $(n=337)$ & $-0.1 \pm 1.4$ & $-0.3 \pm 1.3$ & 0.429 \\
\hline FEV , decline $(\mathrm{mL} /$ year, $\mathrm{n}=337)$ & $-25.9 \pm 26.1$ & $-23.7 \pm 24.4$ & 0.456 \\
\hline
\end{tabular}

Notes: Data are presented as $\mathrm{n}(\%)$ or mean \pm SD. *Indicated $P$-value $<0.05$.

Abbreviations: SD, standard deviation; BMI, body mass index; BA, bronchial asthma; FEV , forced expiratory volume in I second; 6MWD, 6 min walk distance; mMRC, modified Medical Research Council; SGRQ, St. George's Respiratory Questionnaire. 
Table 3 Comparison of exacerbation and mortality according to symptom variability

\begin{tabular}{|c|c|c|c|c|}
\hline Parameter & $\begin{array}{l}\text { Total } \\
(\mathrm{N}=407)\end{array}$ & $\begin{array}{l}\text { Consistent group } \\
(n=137)\end{array}$ & $\begin{array}{l}\text { Variable group } \\
(n=270)\end{array}$ & $P$-value \\
\hline History of AE-COPD in previous I year $(n=391)$ & $77(19.7)$ & $24(19.0)$ & $53(20.0)$ & 0.825 \\
\hline Follow-up duration, days* & $2180.3 \pm 1217.0$ & $1968.4 \pm 1220.4$ & $2287.8 \pm 1203.3$ & 0.012 \\
\hline AE-COPD* & $247(60.7)$ & $69(50.4)$ & $178(65.9)$ & 0.002 \\
\hline AE-COPD/year & $0.9 \pm 2.9$ & $0.5 \pm 1.0$ & $1.1 \pm 3.5$ & 0.078 \\
\hline Severe AE-COPD* & $96(23.6)$ & $20(14.6)$ & $76(28.1)$ & 0.002 \\
\hline Severe AE-COPD/year* & $0.2 \pm 0.6$ & $0.1 \pm 0.2$ & $0.2 \pm 0.7$ & 0.002 \\
\hline Annual exacerbator* & $120(29.5)$ & $26(19)$ & $94(34.8)$ & 0.001 \\
\hline Frequent exacerbator* & $56(13.8)$ & II (8.0) & $45(16.7)$ & 0.017 \\
\hline Death $(n=329)$ & $5 I(15.5)$ & $13(11.5)$ & $38(17.6)$ & 0.147 \\
\hline
\end{tabular}

Note: *Indicated $P$-value $<0.05$.

Abbreviations: AE-COPD, acute exacerbation of chronic obstructive pulmonary disease; annual exacerbator, $A E-C O P D / y e a r ~ \geq 1$; frequent exacerbator, AE-COPD/year $\geq 2$ or severe AE-COPD/year $\geq 1$.
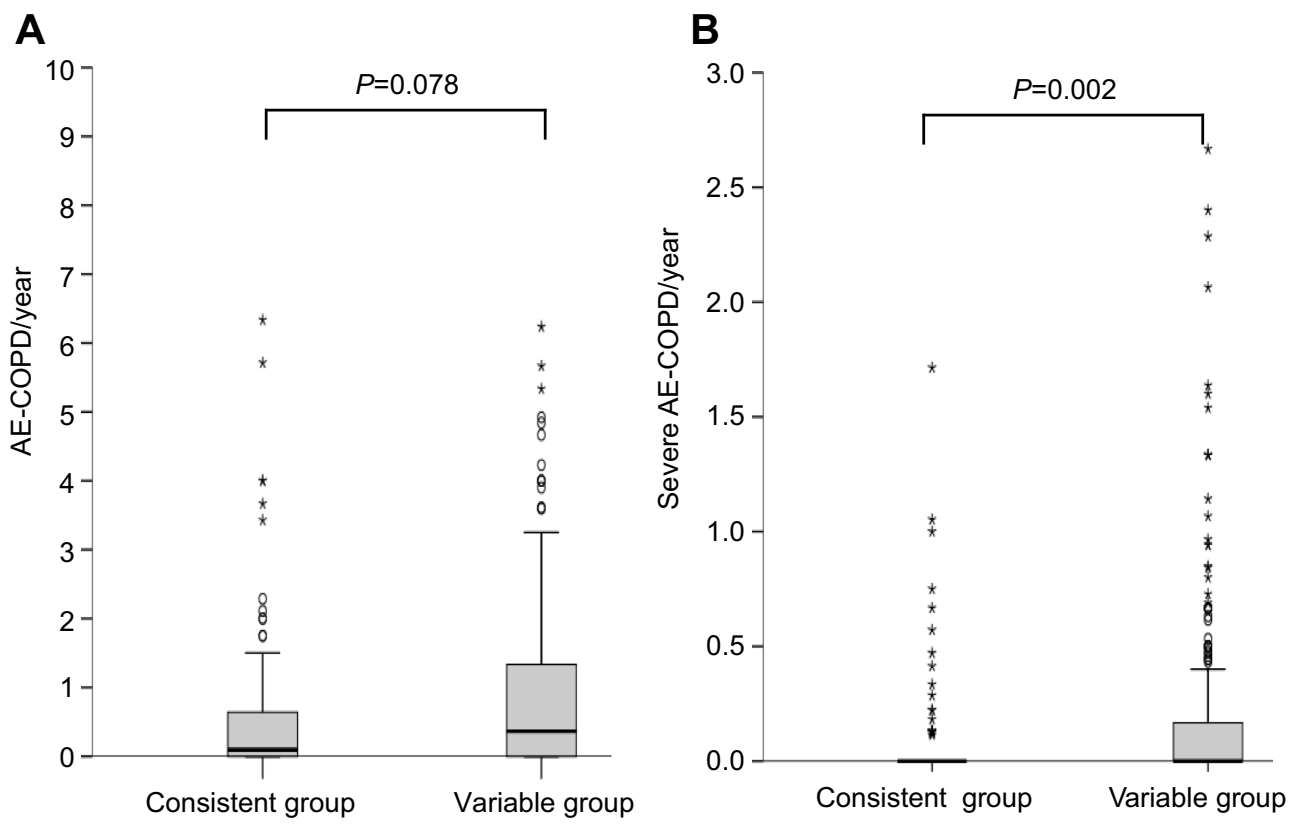

Figure I The annual incidence of exacerbations according to symptom variability: the annual incidence of AE-COPD (A) and the annual incidence of severe AE-COPD (B). The variable group tended to show higher incidences of AE-COPD per year (A) and severe AE-COPD per year (B) when compared to the consistent group. ${ }^{*}$ Highly suspected outliers; ${ }^{\circ}$ suspected outliers.

Abbreviation: AE-COPD, acute exacerbation of chronic obstructive pulmonary disease.

In logistic regression analysis, BMI was the only significant factor for frequent exacerbators (Table 5). Being in the variable group and lung function $\left(\mathrm{FEV}_{1}\right)$ tended to be associated with frequent exacerbators $(\mathrm{OR}=2.090$, $P=0.055$ and $\mathrm{OR}=0.983, P=0.096$; respectively).

\section{Association of symptom variability with mortality}

Kaplan-Meier survival analysis showed no significant relationship between mortality risk and symptom variability $(P=0.505$, Figure S2). Cox-proportional hazard ratio analysis revealed that symptom variability was not significantly associated with mortality (Table 6). Meanwhile, frequent exacerbators were significantly associated with mortality as well as age, smoking amount, BMI, and mMRC score.

\section{Discussion}

The 2017 GOLD proposed a new "ABCD” grouping method based on severity of COPD symptoms and exacerbation history during the past year. The severity of COPD symptoms were assessed by mMRC or CAT ${ }^{\mathrm{TM}}$. Because of the 

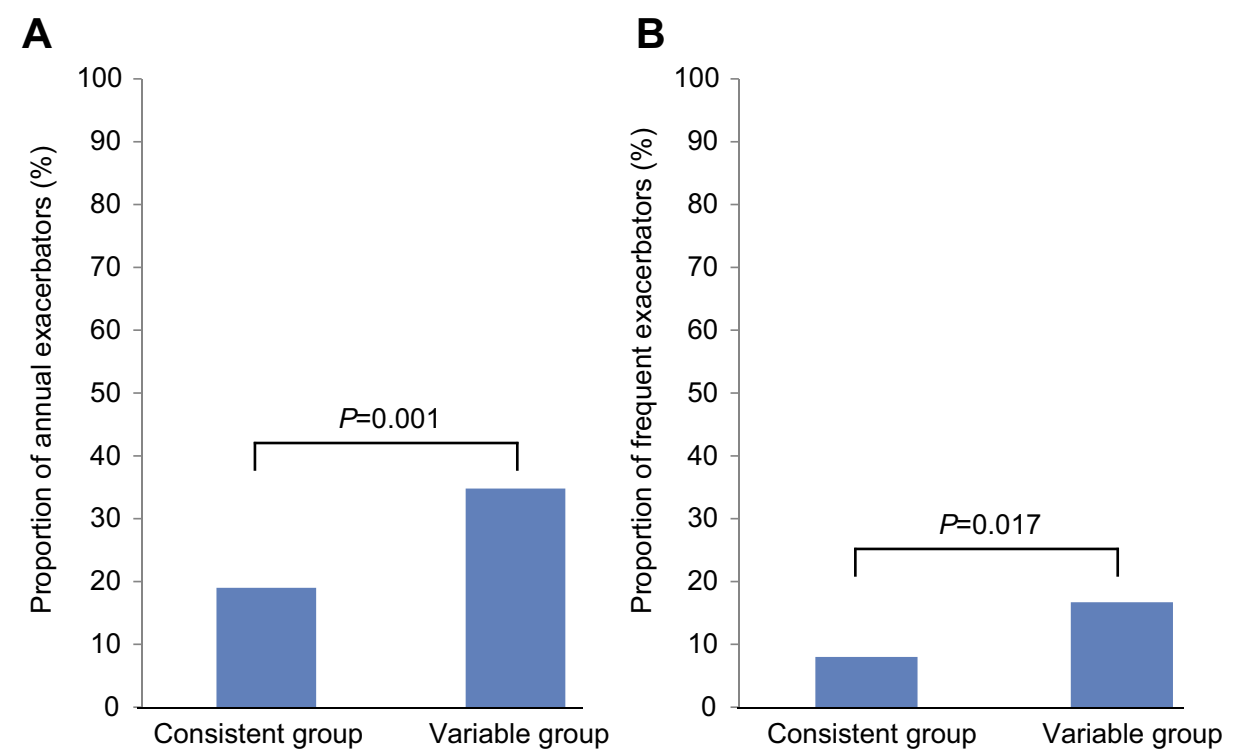

Figure 2 The proportion of annual exacerbators $(\mathbf{A})$ and frequent exacerbators $(\mathbf{B})$ according to symptom variability. The variable group showed higher proportions of annual exacerbators $(\mathbf{A})$ and more frequent exacerbators $(\mathbf{B})$ compared to the consistent group.

Abbreviations: Annual exacerbator, AE-COPD/year $\geq 1$; frequent exacerbator, $A E-C O P D / y e a r ~ \geq 2$ or severe $A E-C O P D / y e a r ~ \geq I$.

Table 4 Risk factors associated with annual exacerbator

\begin{tabular}{|c|c|c|c|c|c|c|}
\hline \multirow[t]{2}{*}{ Parameter $(n=390)$} & \multicolumn{3}{|c|}{ Univariate } & \multicolumn{3}{|c|}{ Multivariate } \\
\hline & OR & $95 \% \mathrm{Cl}$ & $P$-value & OR & $95 \% \mathrm{Cl}$ & $P$-value \\
\hline Age, years & 1.032 & $1.003-1.062$ & 0.031 & 1.025 & $0.993-1.058$ & 0.130 \\
\hline Male & 0.833 & $0.205-3.386$ & 0.798 & & & \\
\hline Smoking amount, pack-year & 1.008 & $1.000-1.016$ & 0.057 & 1.007 & $0.999-1.016$ & 0.103 \\
\hline Current smoker & 0.851 & $0.526-1.375$ & 0.510 & & & \\
\hline BMI, $\mathrm{kg} / \mathrm{m}^{2}$ & $0.94 I$ & $0.880-1.007$ & 0.078 & 0.980 & $0.909-1.057$ & 0.601 \\
\hline Family history of BA & 1.033 & $0.57 I-1.868$ & 0.915 & & & \\
\hline $\mathrm{FEV}_{\mathrm{I}}(\%$ predicted)* & 0.978 & $0.965-0.990$ & 0.001 & 0.982 & $0.968-0.996$ & 0.012 \\
\hline 6MWD, m & 0.999 & $0.997-1.002$ & 0.534 & & & \\
\hline Charlson's comorbidity score & 0.917 & $0.650-1.295$ & 0.624 & & & \\
\hline Blood eosinophil count $\left(/ \mathrm{mm}^{3}\right)$ & 1.000 & $0.999-1.000$ & 0.423 & & & \\
\hline mMRC, initial & 1.333 & $1.070-1.660$ & 0.010 & 1.058 & $0.831-1.347$ & 0.645 \\
\hline SD of mMRC during I year & 2.015 & $1.198-3.392$ & 0.008 & & & \\
\hline Variable group (vs Consistent group)* & 2.280 & $1.390-3.74 \mid$ & 0.001 & 1.963 & $1.165-3.305$ & 0.011 \\
\hline History of AE-COPD in previous I year* & 2.282 & $1.365-3.813$ & 0.002 & 2.036 & $1.185-3.499$ & 0.010 \\
\hline
\end{tabular}

Note: *Indicated $P$-value $<0.05$.

Abbreviations: Annual exacerbator, AE-COPD/year $\geq 1$; BMI, body mass index; FEV , forced expiratory volume in I second; 6 MWD, 6 min walk distance; mMRC, modified Medical Research Council; SD, standard deviation; AE-COPD, acute exacerbation of chronic obstructive pulmonary disease; OR, odds ratio; Cl, confidential interval.

new grouping, increasing attention has been focused on the COPD symptoms, which was believed to be persistent and progressive in nature. ${ }^{17}$ In this study, we found that COPD patients with symptom variability (the variable group) experienced more frequent exacerbations during the followup period, and frequent exacerbators were associated with death. Also, the variable group showed lower lung function, worse dyspnea symptom, and poorer quality of life.
Especially, the variable group has approximately a 2-fold increased risk of annual exacerbators regardless of lung function and previous exacerbation history, which were well-known predictors of COPD exacerbations. ${ }^{18}$ However, we could not find any significant association between symptom variability and mortality. Instead, we found that frequent exacerbators had an approximately 2-fold higher risk of death as well as age, smoking amount, BMI, and mMRC 
Table 5 Risk factors associated with frequent exacerbator

\begin{tabular}{|c|c|c|c|c|c|c|}
\hline \multirow[t]{2}{*}{ Parameter $(n=370)$} & \multicolumn{3}{|c|}{ Univariate } & \multicolumn{3}{|c|}{ Multivariate } \\
\hline & OR & $95 \% \mathrm{Cl}$ & $P$-value & OR & $95 \% \mathrm{Cl}$ & $P$-value \\
\hline Age, years & 1.033 & $0.994-1.073$ & 0.097 & 1.017 & $0.972-1.064$ & 0.464 \\
\hline Male & 0.549 & $0.111-2.714$ & 0.462 & & & \\
\hline Smoking amount, pack-year & 0.998 & $0.987-1.010$ & 0.792 & & & \\
\hline Current smoker & 1.068 & $0.576-1.977$ & 0.835 & & & \\
\hline $\mathrm{BMI}, \mathrm{kg} / \mathrm{m}^{2^{*}}$ & 0.849 & $0.774-0.931$ & 0.001 & 0.900 & $0.812-0.998$ & 0.045 \\
\hline Family history of BA & 1.361 & $0.657-2.819$ & 0.407 & & & \\
\hline FEV (\% predicted) & 0.971 & $0.954-0.988$ & 0.001 & 0.983 & $0.964-1.003$ & 0.096 \\
\hline 6MWD, m & 0.996 & $0.993-1.000$ & 0.024 & 0.998 & $0.994-1.003$ & 0.427 \\
\hline Charlson's comorbidity score & 0.798 & $0.475-1.342$ & 0.395 & & & \\
\hline Blood eosinophil count $\left(/ \mathrm{mm}^{3}\right)$ & 0.999 & $0.997-1.000$ & 0.112 & & & \\
\hline mMRC, initial & 1.317 & $0.991-1.749$ & 0.057 & 0.985 & $0.698-1.389$ & 0.930 \\
\hline SD of mMRC during I year & 2.171 & $1.117-4.219$ & 0.022 & & & \\
\hline Variable group (vs Consistent group) & 2.291 & I.144-4.587 & 0.019 & 2.090 & $0.983-4.440$ & 0.055 \\
\hline History of $A E-C O P D$ in previous I year & 1.998 & $1.059-3.768$ & 0.033 & 1.732 & $0.874-3.432$ & 0.115 \\
\hline
\end{tabular}

Note: *Indicated $P$-value $<0.05$.

Abbreviations: Frequent exacerbator, AE-COPD/year $\geq 2$ or severe AE-COPD/year $\geq 1$; BMI, body mass index; FEV , forced expiratory volume in I second; $6 \mathrm{MWD}$, 6 min walk distance; mMRC, modified Medical Research Council; SD, standard deviation; AE-COPD, acute exacerbation of chronic obstructive pulmonary disease; OR, odds ratio; $\mathrm{Cl}$, confidential interval.

Table 6 Risk factors associated with death

\begin{tabular}{|c|c|c|c|c|c|c|}
\hline \multirow[t]{2}{*}{ Parameter $(n=309)$} & \multicolumn{3}{|c|}{ Univariate } & \multicolumn{3}{|c|}{ Multivariate } \\
\hline & HR & $95 \% \mathrm{Cl}$ & $P$-value & HR & $95 \% \mathrm{Cl}$ & $P$-value \\
\hline Age, years* & 1.165 & $1.110-1.222$ & $<0.001$ & 1.113 & $1.057-1.173$ & $<0.001$ \\
\hline Male & 1.221 & $0.168-8.862$ & 0.843 & & & \\
\hline Smoking amount, pack-year* & 1.011 & $1.003-1.020$ & 0.007 & 1.011 & $1.002-1.020$ & 0.016 \\
\hline Current smoker & 0.817 & $0.409-1.63 \mid$ & 0.566 & & & \\
\hline BMI, $\mathrm{kg} / \mathrm{m}^{2^{*}}$ & 0.773 & $0.708-0.843$ & $<0.001$ & 0.835 & $0.756-0.923$ & $<0.001$ \\
\hline Family history of BA & 1.055 & $0.511-2.179$ & 0.884 & & & \\
\hline FEV (\% predicted) & 0.953 & $0.935-0.97 \mid$ & $<0.001$ & 0.984 & $0.963-1.005$ & 0.133 \\
\hline 6MWD, m & 0.992 & $0.989-0.995$ & $<0.001$ & 0.999 & $0.995-1.003$ & 0.662 \\
\hline Charlson's comorbidity score & 0.963 & $0.582-1.593$ & 0.883 & & & \\
\hline Blood eosinophil count $\left(/ \mathrm{mm}^{3}\right)$ & 0.999 & $0.998-1.000$ & 0.168 & & & \\
\hline mMRC, initial* & 2.509 & $1.829-3.443$ & $<0.001$ & 1.540 & $1.072-2.212$ & 0.019 \\
\hline SD of mMRC during I year & 1.312 & $0.642-2.685$ & 0.456 & & & \\
\hline Variable group (vs Consistent group) & 1.239 & $0.660-2.327$ & 0.505 & & & \\
\hline History of AE-COPD in previous I year & 2.025 & I.109-3.700 & 0.022 & 0.664 & $0.323-1.365$ & 0.265 \\
\hline Frequent exacerbator* & 3.244 & $1.794-5.865$ & $<0.001$ & 2.119 & I.103-4.072 & 0.024 \\
\hline
\end{tabular}

Note: *Indicated $P$-value $<0.05$.

Abbreviations: BMI, body mass index; $\mathrm{FEV}_{1}$, forced expiratory volume in I second; 6MWD, 6 min walk distance; mMRC, modified Medical Research Council; SD, standard deviation; AE-COPD, acute exacerbation of chronic obstructive pulmonary disease; Frequent exacerbator, AE-COPD/year $\geq 2$ or severe $A E-C O P D / y e a r ~ \geq I$; OR, odds ratio; $\mathrm{Cl}$, confidential interval.

scores. This implicates that symptom variability might not be directly associated with mortality, but could influence death via increasing risk of frequent exacerbations.

It has been known that COPD patients having daily symptom variability, usually worsening in the morning, have more severe disease status, such as decreased physical activity, decreased HRQOL scores, and increased exacerbation. $^{2-9}$ However, there are some limitations in the previous studies that symptom variability was only assessed during the day using the question, "Do you have symptom variability during the day or week?" Our study has strengths over the previous ones in this point, 
using numerical symptom scores measured by $\mathrm{mMRC}$ in a longitudinal cohort every 3 months and arithmetical calculation of SD values in each patient. In the analysis, we used mMRC scores obtained during the 1-year follow-up period because Korea has 4 distinct seasons, which might influence symptom fluctuation. Also, calculation bias of SD was avoided by simplifying the number of mMRC scores of each patient because SD values were influenced by the total number of measurements. To the best of our knowledge, this is the first study to investigate clinical impacts of longitudinal symptom score variability on long-term outcomes, such as exacerbation and death. Our findings provide evidence for clinical implications of longitudinal symptom variability in COPD.

There might be confusion that COPD with symptom variability is a type of asthma-COPD overlap (ACO). However, it is conceivable that the variable group showed characteristics distinguishable from ACO by demonstrating no significant differences in asthmatic features, such as family history of asthma, comorbidity, bronchodilator response of $\mathrm{FEV}_{1}$ (data were not shown in the result), and blood eosinophils. ${ }^{19,20}$ In addition, the variable group is not a population of symptom worsening because the decline in SGRQ scores did not differ according to symptom variability. Also, the decline in $\mathrm{FEV}_{1}$ was not different between the 2 groups, indicating that patients in the variable group are distinguishable from COPD patients suffering from lung function decline. Taken together, symptom variability, but not ACO features, worsening of symptoms, or lung function decline, might be a new distinct indicator of exacerbation-prone COPD. ${ }^{21}$

Also, there is a question whether symptom variability is distinguishable from exacerbation. This argument can be answered by the definition of acute exacerbation of COPD in the GOLD guideline-an acute worsening of respiratory symptoms that requires additional medications, ${ }^{1}$ while symptom variability does not result in treatment change. From the beginning of the KOLD cohort, we did not collect clinical data at each visit when patients were in an exacerbated status and we double-checked the clinical data by collecting medication data at each visit. In other words, if patient had been taking or would be taking medications due to symptom exacerbation at each visit, we skipped data collection. Also, we used mMRC data during the 1-year follow-up period and exacerbation was assessed during the total follow-up period of 2,180.3 \pm 1217.0 days (remarkably longer duration). Additionally, there were no differences in history of AE-COPD between the consistent and variable groups during the previous year ( $19.0 \%$ vs $20.0 \%, P=0.825$ ), indicating that the symptom variability is distinguishable from exacerbation as defined in this study. Moreover, time to the first COPD exacerbation was shorter in the variable group than in the consistent group for symptom variability during the follow-up period (Figure S1).

However, it is conceivable that acute exacerbation might influence symptom variability, because patient's symptoms would be aggravated before exacerbation and could persist for a while. ${ }^{22}$ Also, approximately $50 \%$ of the exacerbations are not reported to clinicians, even though the aggravation of symptoms is not different from reported exacerbations. ${ }^{23}$ For these reasons, the decline in mMRC scores in some patients might represent symptom aggravation before and after exacerbation or unreported exacerbation. Despite the limitations in real-world practice that symptom variability is not clearly differentiated from exacerbation, this study is valuable in that symptom variability without medication change could be a risk factor for COPD exacerbation and poor prognosis regardless of lung function and previous exacerbation history.

This study has weakness that symptom variability was assessed only by using the mMRC dyspnea scoring system. Even though mMRC dyspnea scale correlates well with other measures of patient disability ${ }^{24}$ and predicts future mortality, ${ }^{25}$ it is currently believed that COPD causes respiratory symptoms including dyspnea in some patients. Therefore, overall symptoms might be more appropriate for the assessment of symptom variability than dyspnea alone. However, since SGRQ is too complex to be completed at each visit, most of the researchers of the KOLD cohort perform SGRQ only once a year and the Korean version of CAT was not available when this cohort study was started. Therefore, we used mMRC scores for the measurement of symptom variability. In addition, our cohort predominantly consisted of male patients (97.8\%), so that the results cannot be automatically generalized to the entire population because male tend to had poor awareness of COPD. ${ }^{26}$

To our knowledge, this is the first study to investigate the impact of the longitudinal symptom variability of COPD by using objective measures and calculations of regularly checked mMRC scores. In this study, we found that a new parameter, symptom variability during the follow-up period, could predict frequent exacerbations of COPD. This finding assisted in medication escalation or de-escalation for the treatment of COPD according to the 
recent GOLD guideline. ${ }^{1}$ If the patients are carefully observed for the occurrence of symptom variability following medication de-escalation, future exacerbation risk can be predicted and the exacerbation may be prevented through early re-escalation of medications.

\section{Conclusion}

COPD patients with symptom variability have lower lung functions and worse respiratory symptoms. Also, they tend to be exacerbated at least once a year and to experience more frequent exacerbations compare to those with consistent symptoms.

\section{Disclosure}

The authors report no conflicts of interest in this work.

\section{References}

1. Global Initiative for Chronic Obstructive Lung Disease. Global Strategy for the Diagnosis, Management and Prevention of COPD, Global Initiative for Chronic Obstructive Lung Disease (GOLD) 2019. Available from: http://goldcopd.org. Accessed April 5, 2019.

2. Kessler R, Partridge MR, Miravitlles M, et al. Symptom variability in patients with severe COPD: a pan-European cross-sectional study. Eur Respir J. 2011;37(2):264-272. doi:10.1183/09031936.00051110

3. Espinosa de los Monteros MJ, Peña C, Soto Hurtado EJ, Jareño J, Miravitlles M. Variability of respiratory symptoms in severe COPD. Arch Bronconeumol. 2012;48(1):3-7. doi:10.1016/j.arbr.2011.07.006

4. Kim YJ, Lee BK, Jung CY, et al. Patient's perception of symptoms related to morning activity in chronic obstructive pulmonary disease: the SYMBOL Study. Korean J Intern Med. 2012;27(4):426-435. doi:10.3904/kjim.2012.27.4.426

5. Partridge MR, Karlsson N, Small IR. Patient insight into the impact of chronic obstructive pulmonary disease in the morning: an internet survey. Curr Med Res Opin. 2009;25(8):2043-2048. doi:10.1185/ 03007990903103006

6. Tsiligianni I, Metting E, van der Molen T, Chavannes N, Kocks J. Morning and night symptoms in primary care COPD patients: a cross-sectional and longitudinal study. An UNLOCK study from the IPCRG. NPJ Prim Care Respir Med. 2016;26:16040. doi:10.1038/ npjpcrm.2016.40

7. Miravitlles M, Worth H, JJS C, et al. Observational study to characterise 24-hour COPD symptoms and their relationship with patientreported outcomes: results from the ASSESS study. Respir Res. 2014;15(1):122. doi:10.1186/s12931-014-0122-1

8. van Buul AR, Kasteleyn MJ, Chavannes NH, Taube C. Association between morning symptoms and physical activity in COPD: a systematic review. Eur Respir Rev. 2017;26(143):160033. doi:10.1183/ 16000617.0033-2016

9. Lopez-Campos JL, Calero C, Quintana-Gallego E. Symptom variability in COPD: a narrative review. Int J Chron Obstruct Pulmon Dis. 2013;8:231-238. doi:10.2147/COPD.S42866

10. Timmins SC, Coatsworth N, Palnitkar G, et al. Day-to-day variability of oscillatory impedance and spirometry in asthma and COPD. Respir Physiol Neurobiol. 2013;185(2):416-424. doi:10.1016/j.resp.2012.08.017
11. Rothwell PM, Howard SC, Dolan E, et al. Effects of $\beta$ blockers and calcium-channel blockers on within-individual variability in blood pressure and risk of stroke. Lancet Neurol. 2010;9(5):469-480. doi:10.1016/S1474-4422(10)70066-1

12. Sunwoo JS, Yang TW, Kim DY, et al. Association of blood pressure variability with orthostatic intolerance symptoms. PLoS One. 2017;12(6):e0179132. doi:10.1371/journal.pone.0179132

13. Park TS, Lee JS, Seo JB, et al. Study design and outcomes of Korean Obstructive Lung Disease (KOLD) cohort study. Tuberc Respir Dis (Seoul). 2014;76(4):169-174. doi:10.4046/trd.2014.76.4.169

14. Kim WJ, Oh Y-M, Sung J, et al. Lung function response to 12-week treatment with combined inhalation of long-acting $\beta 2$ agonist and glucocorticoid according to ADRB2 polymorphism in patients with chronic obstructive pulmonary disease. Lung. 2008;186(6):381-386. doi:10.1007/s00408-008-9103-9

15. Crapo RO, Hankinson JL, Irvin C, et al. Standardization of spirometry: 1994 update. Am J Respir Crit Care Med. 1995;152(3):11071136. doi:10.1164/ajrccm.152.3.7663792

16. Kim J, Yoon HI, Oh YM, et al. Lung function decline rates according to GOLD group in patients with chronic obstructive pulmonary disease. Int J Chron Obstruct Pulmon Dis. 2015;10:1819-1827.

17. Martinez FJ, Abrahams RA, Ferguson GT, et al. Effects of baseline symptom burden on treatment response in COPD. Int J Chron Obstruct Pulmon Dis. 2019;14:181-194. doi:10.2147/COPD.S179912

18. Hurst J, Vestbo J, Anzueto A, et al. Susceptibility to exacerbation in chronic obstructive pulmonary disease. $N$ Engl $J$ Med. 2010;363:1128-1138. doi:10.1056/NEJMoa0909883

19. Boulet LP, Boulay ME, Milot J, Lepage J, Bilodeau L, Maltais F. Longitudinal comparison of outcomes in patients with smokingrelated asthma-COPD overlap and in non-smoking asthmatics with incomplete reversibility of airway obstruction. Int J Chron Obstruct Pulmon Dis. 2019;14:493-498. doi:10.2147/COPD.S192003

20. Müllerová H, Meeraus WH, Galkin DV, Albers FC, Landis SH. Clinical burden of illness among patients with severe eosinophilic COPD. Int $J$ Chron Obstruct Pulmon Dis. 2019;14:741-755. doi:10.2147/COPD.S194511

21. Kania A, Krenke R, Kuziemski K, et al. Distribution and characteristics of COPD phenotypes - results from the Polish sub-cohort of the POPE study. Int $J$ Chron Obstruct Pulmon Dis. 2018;13:1613-1621.

22. Seemungal TA, Donaldson GC, Bhowmik A, Jeffries DJ, Wedzicha JA. Time course and recovery of exacerbations in patients with chronic obstructive pulmonary disease. Am J Respir Crit Care Med. 2000;161(5):1608-1613. doi:10.1164/ajrccm.161.5.9908022

23. Seemungal TA, Donaldson GC, Paul EA, Bestall JC, Jeffries DJ, Wedzicha JA. Effect of exacerbation on quality of life in patients with chronic obstructive pulmonary disease. Am J Respir Crit Care Med. 1998;157(5):1418-1422. doi:10.1164/ajrccm.157.5.9709032

24. Bestall JC, Paul EA, Garrod R, Garnham R, Jones PW, Wedzicha JA. Usefulness of the Medical Research Council (MRC) dyspnoea scale as a measure of disability in patients with chronic obstructive pulmonary disease. Thorax. 1999;54(7):581-586. doi:10.1136/ thx.54.7.581

25. Nishimura K, Izumi T, Tsukino M, Oga T. Dyspnea is a better predictor of 5-year survival than airway obstruction in patients with COPD. Chest. 2002;121(5):1434-1440. doi:10.1378/chest.12 1.5.1434

26. Hwang YI, Park YB, Yoon HK, et al. Male current smokers have low awareness and optimistic bias about COPD: field survey results about COPD in Korea. Int J Chron Obstruct Pulmon Dis. 2019;14:271277. doi:10.2147/COPD.S189859 


\section{Supplementary materials}

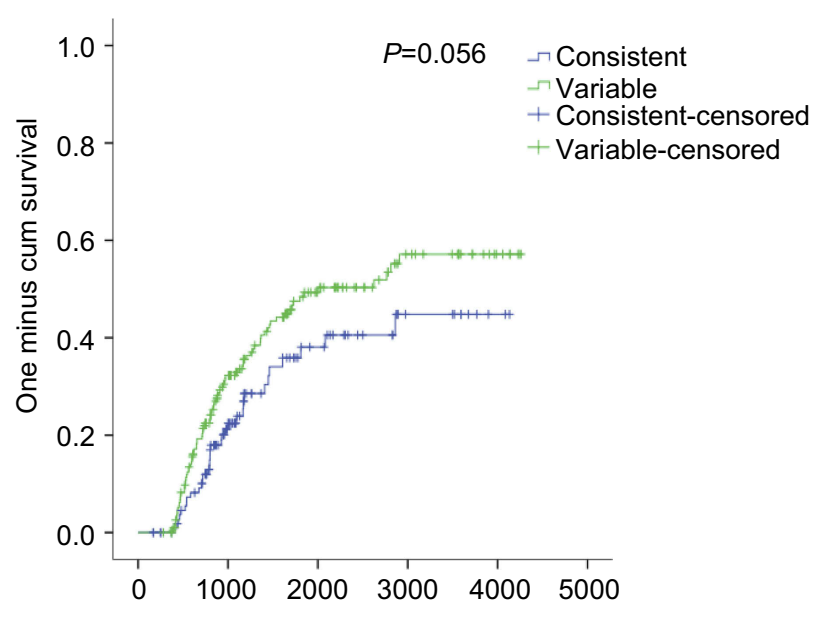

Figure SI Survival function curves of time to the first exacerbation according to symptom variability. Time to the first exacerbation was shorter in the variable group than in the consistent group, for symptom variability during the follow-up period $(P=0.056)$.

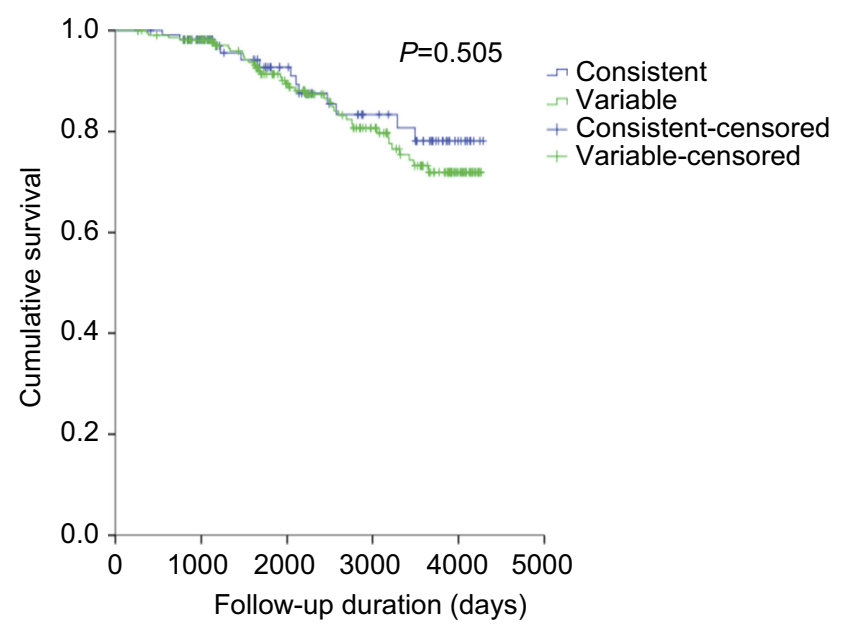

Figure S2 Survival function curves according to symptom variability. There was no significant difference in survival rates between the variable and consistent groups.

International Journal of Chronic Obstructive Pulmonary Disease

\section{Publish your work in this journal}

The International Journal of COPD is an international, peer-reviewed journal of therapeutics and pharmacology focusing on concise rapid reporting of clinical studies and reviews in COPD. Special focus is given to the pathophysiological processes underlying the disease, intervention programs, patient focused education, and self management protocols. This journal is indexed on PubMed Central, MedLine and CAS. The manuscript management system is completely online and includes a very quick and fair peer-review system, which is all easy to use. Visit http://www.dovepress.com/testimonials.php to read real quotes from published authors. 